\title{
GISP Preface
}

The process-based view is now an established paradigm for the design of organizations and their supportive systems. Business process management (BPM) is the discipline that comprises the set of methodologies, tools and techniques which facilitate the enterprise-wide establishment of process capabilities and projectspecific process lifecycle management support. Over the last decade, the field of BPM has matured substantially in terms of its practical uptake and impact as well as in terms of the corresponding academic body of knowledge. The Information Systems discipline has become a main intellectual home for BPM-related research and BPM as a topic has inspired fruitful new research directions.

However, an increasingly globalized world leads to new demands, and the domain of BPM is no exception. The design of processes needs to be tailored to the regional circumstances, while headquarters of multi-national organizations are aiming towards global process standards.

The First Conference on Global Information Systems Processes was dedicated to the development of a better understanding of the differences in which organizations adopt the process-centered approach. This covers both the detailed analysis of the adoption in a specific region with an individual cultural and legislative setting as well as the rollout of business processes in multinational corporations.

Jointly organized with the E-Government and E-Services Conference, GISP 2010 attracted 13 submissions that were all reviewed by $2-3$ carefully selected expert reviewers. As part of a competitive process, we selected six papers ( $46 \%$ acceptance rate) for inclusion in the inaugural GISP program. These papers cover both of the facets of global process design. First, we have four papers covering global case studies on process design issues. These cases cover the contextual settings of Singapore, Kuwait, Finland and South Africa. Second, two papers deal with the challenge of globalized process design, i.e., the demands of large-scale process models as they emerge in global projects and an investigation of a process design project covering two continents. A panel discussion on "Process Design in an Increasingly Globalized Society" completed the program.

We are grateful to all authors of submitted papers. The quality of the submissions in such a young field was high, making the paper selection a difficult task. We are grateful to the careful revisions that were conducted by the authors of successful papers. In particular, we would like to thank all of our reviewers. Their critical feedback and constructive inspirations were a key success factor for this conference. 
The challenges of process design in a globalized world will remain of high significance in the coming years. We hope that the contents presented and discussed at this conference will provide guidance for practitioners and academics involved in this field.

September 2010

Jan Pries-Heje

Michael Rosemann 